\title{
Are there sex differences among colorectal cancer patients in treatment and survival? A Swiss cohort study
}

\author{
Manuela Limam ${ }^{1,2} \cdot$ Katarina Luise Matthes $^{1,2} \cdot$ Giulia Pestoni $^{1,2}$ (D) Eleftheria Michalopoulou ${ }^{1} \cdot$ Leonhard Held $^{1}(\mathbb{D})$ \\ Silvia Dehler ${ }^{1,2} \cdot$ Dimitri Korol $^{2} \cdot$ Sabine Rohrmann ${ }^{1,2} \mathbb{0}$
}

Received: 4 September 2020 / Accepted: 4 February 2021 / Published online: 4 March 2021

(c) The Author(s) 2021

\begin{abstract}
Background Colorectal cancer (CRC) is among the three most common incident cancers and causes of cancer death in Switzerland for both men and women. To promote aspects of gender medicine, we examined differences in treatment decision and survival by sex in CRC patients diagnosed 2000 and 2001 in the canton of Zurich, Switzerland.

Methods Characteristics assessed of 1076 CRC patients were sex, tumor subsite, age at diagnosis, tumor stage, primary treatment option and comorbidity rated by the Charlson Comorbidity Index (CCI). Missing data for stage and comorbidities were completed using multivariate imputation by chained equations. We estimated the probability of receiving surgery versus another primary treatment using multivariable binomial logistic regression models. Univariable and multivariable Cox proportional hazards regression models were used for survival analysis.

Results Females were older at diagnosis and had less comorbidities than men. There was no difference with respect to treatment decisions between men and women. The probability of receiving a primary treatment other than surgery was nearly twice as high in patients with the highest comorbidity index, CCI $2+$, compared with patients without comorbidities. This effect was significantly stronger in women than in men $(p$-interaction $=0.010)$. Survival decreased with higher CCI, tumor stage and age in all CRC patients. Sex had no impact on survival.

Conclusion The probability of receiving any primary treatment and survival were independent of sex. However, female CRC patients with the highest CCI appeared more likely to receive other therapy than surgery compared to their male counterparts.
\end{abstract}

Keywords Colorectal cancer $\cdot$ Sex differences $\cdot$ Comorbidity $\cdot$ Treatment $\cdot$ Survival

Abbreviations
CRC
CCI
AHA
ICD

TNM (Classification of malignant tumors)

RCC

LCRC

Sabine Rohrmann

Sabine.Rohrmann@usz.ch

1 Epidemiology, Biostatistics and Prevention Institute, University of Zurich, Zurich, Switzerland

2 Cancer Registry Zurich, Zug, Schaffhausen and Schwyz, University Hospital Zurich, Zurich, Switzerland
Mice

Colorectal cancer

Charlson Comorbidity Index

American Heart Association

International Classification

of Diseases

Tumor, lymph nodes, metastasis

Right-sided colon cancer

Left-sided colorectal cancer

\section{Background}

\author{
Multivariate imputation by \\ chained equations \\ Missing not at random \\ Odds ratio \\ Confidence interval \\ Hazard ratio \\ World Health Organization \\ Body mass index
}

About 4000 cases of colorectal cancer (CRC) are diagnosed in Switzerland every year, making it one of the three most common incident cancers, which is in line with the world cancer incidence report (Forman et al. 2013). Despite a decreasing mortality for both men and women, as recently reported for Switzerland (Bordoni et al. 2012), this cancer 
entity is still within the three most common causes of cancer death.

Investigations into differences of biological, behavioral and environmental factors between men and women and their impact on the manifestation, mechanism, treatment and outcome of disease is the task of gender medicine. Cardiology is one of the medical specialties pioneering scientific work done to establish and finally apply sex differences in the development and prevention of cardiovascular diseases, the awareness and presentation of their symptoms, and the effectiveness of therapy. In recent years, investigations in France have shown that the risk of women of developing cardiovascular diseases has been underestimated (MounierVehier et al. 2010). In addition, an increasing proportion of women younger than 60 years of age with an acute coronary syndrome has been observed (Puymirat et al. 2012). Therefore, a gynecologist and a cardiologist working in the University hospital of Lille in France have introduced a care pathway "heart, arteries and women" for women with high cardiovascular risk (Mounier-Vehier et al. 2014). According to the recommendations of the American Heart Association (AHA) and the European Society of Cardiology, women should be carefully followed in their three phases of hormonal life: contraception, pregnancy and perimenopause.

In oncology, despite differences between sexes with respect to incidence rates, clinical presentation and prognosis have been described, notably for CRC, no comparable activities in patient care have been set up to the best of our knowledge. More men than women are diagnosed and die from CRC each year (Forman et al. 2013; Lorez et al. 2016). Among CRC patients, women are diagnosed at an older age (Brenner et al. 2007; Paulson et al. 2009) and on average, men are 4-6 years younger at time of death than women (Brenner et al. 2007). Women appear to have a higher risk of developing right-sided CRC than men (Hansen and Jess 2012; Kim et al. 2015; Lee et al. 2015). Several studies have observed an overall survival advantage for women with CRC (McArdle et al. 2003; Paulson et al. 2009; Storli et al. 2011; Wichmann et al. 2001). Comorbidities, diseases mostly diagnosed in older populations, are known to adversely influence treatment decisions and survival in cancer patients in general (Sarfati et al. 2016; Sogaard et al. 2013; Vulto et al. 2006) and in CRC patients (Janssen-Heijnen et al. 2005b; Lemmens et al. 2005a; Munro and Bentley 2004; Sarfati et al. 2009). A study in the Netherlands revealed that among elderly patients with stage III colon cancer diagnosed between 1995 and 2001 females and those with comorbidities were less likely to receive adjuvant treatment (Lemmens et al. 2005b). In a US study, women underwent less aggressive medical therapy in addition to surgery like neoadjuvant and/ or adjuvant treatment for advanced stage rectal and colon cancer than men, particularly in the octogenarian population (Paulson et al. 2009).
Cardiovascular diseases have been categorized for a long time as typically masculine and are often misdiagnosed in women (Hayes 2006). In contrast, pathognomonic symptoms for CRC are probably equally recognized in both men and women. Validated sex differences in cardiovascular diseases which affect men and women have been translated into improved medical prevention and disease care. CRC is also a common disease for which targeted investigations could lead to validation in sex differences to include them in guidelines and disease management. To support aspects of gender medicine, we investigated if differences in primary treatment option and survival by sex exist in Switzerland. To do so, we analyzed cancer registry data of 586 men and 490 women diagnosed with CRC in the years 2000 and 2001.

\section{Methods}

\section{Study population}

The Cancer Registry Zurich, founded in 1980, is an epidemiological tumor registry. Since 1980, all incident cases of cancer in the resident population of the canton of Zurich have been recorded. The canton of Zug joined the registry in 2011; Schaffhausen and Schwyz in 2020. This analysis only used data of the canton of Zurich. Systematically registered variables are cancer site, type of cancer, name, date of birth, sex, place of residence and last date of follow up. The registration of tumor stage, type of therapy and comorbidities was not mandatory for the incidence years in our study.

We extracted 1186 patients diagnosed with CRC as first primary cancer in the years 2000 and 2001 in the canton of Zurich. We excluded all patients registered as death certificate only cases $(N=69,5.8 \%)$, cases identified at autopsy $(N=37,3.1 \%)$ and cases with no specified colon site $(N=4$, $0.3 \%)$. Finally, 1076 CRC cases were included in our study. The CRC cases were classified as C18-C20, based on the ICD-10 key system (International Statistical Classification of Diseases and Related Health Problems). Tumor stage was classified according to the 5th edition of the TNM classification system of the International Union Against Cancer. When no information was available on distant metastasis, we assumed that none existed. The M-category was defined as M zero (Sobin et al. 2009).

We defined two subsites, i.e., proximal or right-sided colon cancer (RCC) and distal or left-sided colorectal cancer (LCRC). RCC consists of tumors of the caecum (C18.0), colon ascendens (C18.2), flexura hepatica (C18.3) and colon transversum (C18.4). LCRC consists of tumors of the flexura lienalis (C18.5), colon descendens (C18.6), colon sigmoideum (C18.7), recto-sigmoid-junction (C19) 
and rectum (C20) (Bufill 1990; Hansen and Jess 2012; Lorez et al. 2016).

The following reasons led to the decision to categorize treatment into surgery and other primary treatment: the low number of cases and the fact that in 2014 optimal surgical resection is still the mainstay in curative CRC treatment, preferably in a multi-modal approach to maintain long-term-survival (Nakayama et al. 2013). Any surgical treatment was included in the surgery group while radiotherapy, radio-chemotherapy, chemotherapy and non-tumor-specific therapy were assigned to other primary treatment. Non-tumor-specific therapy was used when no surgery, radio- and/or chemotherapy were applied. Only the first treatment delivered was included in the analyses. Due to the lack of information on therapy intention, we were not able to define whether the first treatment applied was curative, more specifically neoadjuvant, or palliative. Three age groups were chosen for data analysis $(<65$, $65-74$ and $\geq 75$ ). We obtained patients' vital status from the Citizen Services Departments of the Canton of Zurich. Vital status was recorded until death or for a maximum period of 10 years after diagnosis.

As an additional impact factor, we used the Charlson Comorbidity Index (CCI). Charlson et al. (1987) have developed a classifying system for comorbidities in the form of a weighted index with the purpose to estimate the risk of mortality by taking number and severity of comorbid condition into account. For the original CCI, 19 conditions were defined and a weight as a point score from 1 to 6 was assigned to each of the conditions based on their rounded adjusted relative risk for 1-year mortality. The $\mathrm{CCI}$ is the sum of the weights for all concomitant conditions of a patient. A higher CCI score indicates a higher risk of mortality within 1 year. The weighted comorbidity index is the most widely used comorbidity scoring system in health research and in clinical practice, because it quantifies the individual's disease burden and predicts hospital mortality in an easy way. Many studies have consistently shown that the $\mathrm{CCI}$ is a valid prognostic indicator for mortality (Goldstein et al. 2004; Lee et al. 2005; Myers et al. 2009). In our study, we only took into account the comorbidities present at the time of the CRC diagnosis. The CCI consisted of only 15 conditions, since CRC was the disease of interest and the cancer-related conditions were not taken into account. The points assigned to each of the recorded comorbidities are presented in Table 1. We built three CCI groups adapted to the size of our study population. The point scores for each patient were summed up and used to assign the patient to one of the groups: CCI $0=$ no comorbidities, CCI $1=$ sum of scores equal to 1 , CCI $2+=$ sum of scores equal to 2 or larger.
Table 1 Number of each comorbidity at diagnosis overall and stratified by sex

\begin{tabular}{lrrr}
\hline $\begin{array}{l}\text { Comorbidities (corresponding weight [point } \\
\text { score] for the CCI) }\end{array}$ & All & Male & Female \\
\hline Myocardial infarction (1) & 49 & 36 & 13 \\
Congestive heart failure (1) & 27 & 19 & 8 \\
Peripheral vascular disease (1) & 41 & 27 & 14 \\
Cerebrovascular disease (1) & 43 & 27 & 16 \\
Dementia (1) & 18 & 10 & 8 \\
Chronic lung disease (1) & 36 & 31 & 5 \\
Connective tissue disease (1) & 7 & 2 & 5 \\
Peptic ulcer disease (1) & 29 & 17 & 12 \\
Mild liver disease (1) & 13 & 8 & 5 \\
Diabetes without target organ damage (1) & 61 & 40 & 21 \\
Hemiplegia (2) & 7 & 3 & 4 \\
Moderate to severe renal disease (2) & 24 & 13 & 11 \\
Diabetes with target organ damage (2) & 19 & 16 & 3 \\
Moderate to severe liver disease (3) & 7 & 6 & 1 \\
AIDS (6) & 0 & 0 & 0 \\
Total & 381 & 255 & 126 \\
\hline
\end{tabular}

CCI Charlson Comorbidity Index: the sum of the assigned weights results in the Index for a patient

We obtained information on tumor stage, type of therapy and comorbidity from patient records archived in the registry and from the hospital and the patient's physician.

\section{Statistical methods}

In our data set, 60 (5.6\%) patients had missing information on the T-category, 79 (7.3\%) on the N-category and 312 (29.0\%) had missing information on comorbidities. We had no missing information on treatment. Obtaining information on comorbidities was limited by the time of diagnosis in 2000 and 2001, since medical records in Switzerland are often only stored until 10 years after the patient's death, or the last visit at the practitioner or hospital. To overcome missingness, we used a standard multivariate imputation by chained equations (mice). This method took all variables into account, including the outcome variables: sex, date of diagnosis, age at diagnosis, survival time, vital status, tumor subsite and primary treatment, and the incomplete variables T-category, N-category and CCI (Moons et al. 2006). We created 30 imputed data sets using 10 iterations (Bodner 2008; White et al. 2011).

Studies showed that comorbidity leads to poorer survival in cancer patients in general (Janssen-Heijnen et al. 2005a; Sarfati et al. 2016; Sogaard et al. 2013) as well as in CRC patients (Boakye et al. 2018; Lemmens et al. 2005a). We found that patients without information on CCI had almost twice the risk of dying than patients with information on comorbidity (Supplementary material: Fig. 1S). 
Consequently, we have suspected that the probability of missingness depends on patients' survival and on the unobservable value itself, which means that patients with a higher CCI are likely to have more missing information on comorbidity. Therefore, we assumed that missingness of comorbidity status is MNAR (missing not at random). We performed a sensitivity analysis to evaluate the influence of the unobserved values using $\delta$-adjustment of the imputed data (Van Buuren 2018). Additionally, the results were compared with a complete-case analysis and post hoc sensitivity analysis. Comparison led to similar results and, consequently, we presented only the results obtained using multivariate imputation. After the imputation, we built the TNM tumor stage (I, II, III or IV) for each case from the TNM-categories.

With multivariable binomial logistic regression models we estimated the probability of receiving surgery versus another primary treatment depending on sex, subsite, CCI, tumor stage and age. Univariable and multivariable Cox proportional hazards regression models stratified by sex were performed to assess the effects of age, subsite, CCI, tumor stage and primary treatment option on survival. Since the biological variable sex is at the center of interest, we investigated interaction effects of sex in both the logistic and the Cox regression models. In the binomial logistic regression models, we evaluated the effect of sex on the association of subsite, CCI, tumor stage, age with primary treatment option. In the Cox regression models, we assessed if the impact of our exposure variables on survival depended on sex.

We used the R Version 3.6.0 for all statistical analyses. The R package "mice" (van Buuren and Groothuis-Oudshoorn 2011) was used to impute the missing data, the package "nnet" to perform the binomial logistic regression models (Venables and Ripley 2002), "survival" (Therneau 2015) to perform the Cox regression models. The plotting package "ggplot2" was used to visualize analyses (Wickham 2016).

Table 2 Colorectal cancer patient characteristics ${ }^{\mathrm{a}}$

\begin{tabular}{|c|c|c|c|c|c|c|c|c|c|}
\hline & \multirow[t]{3}{*}{ Total } & \multicolumn{4}{|l|}{ Male } & \multicolumn{4}{|l|}{ Female } \\
\hline & & \multirow[t]{2}{*}{ All } & \multicolumn{3}{|c|}{ CCI (Charlson Comorbidity Index $)^{\mathrm{c}}$} & \multirow[t]{2}{*}{ All } & \multicolumn{3}{|c|}{ CCI (Charlson Comorbidity Index $)^{c}$} \\
\hline & & & 0 & 1 & $2+$ & & 0 & 1 & $2+$ \\
\hline \multicolumn{10}{|c|}{ Tumor site, $n(\%)$} \\
\hline $\mathrm{C} 18-\mathrm{C} 20$ & $1076(100)$ & $586(54.46)$ & $348(59.39)$ & $122(20.82)$ & $116(19.80)$ & $490(45.54)$ & $349(71.22)$ & $85(17.35)$ & $56(11.43)$ \\
\hline $\mathrm{C} 18$ & $672(100)$ & $367(54.61)$ & $205(55.86)$ & $83(22.62)$ & $79(21.53)$ & $305(45.39)$ & $211(69.18)$ & $56(18.36)$ & $38(12.46)$ \\
\hline C19 & $132(100)$ & $66(50.00)$ & $41(62.12)$ & $13(19.70)$ & $12(18.18)$ & $66(50.00)$ & $49(74.24)$ & $11(16.67)$ & $6(9.09)$ \\
\hline $\mathrm{C} 20$ & $272(100)$ & $153(56.25)$ & $102(66.67)$ & $26(16.99)$ & $25(16.34)$ & $119(43.75)$ & $89(74.79)$ & $18(15.13)$ & $12(10.08)$ \\
\hline $\mathrm{RCC}$ & $331(100)$ & $158(47.73)$ & $83(52.53)$ & $38(24.05)$ & $37(23.42)$ & $173(52.27)$ & $105(60.69)$ & $40(23.12)$ & $28(16.18)$ \\
\hline LCRC & $745(100)$ & $428(57.45)$ & $265(61.92)$ & $84(19.63)$ & $79(18.46)$ & $317(42.55)$ & $244(76.97)$ & $45(14.20)$ & $28(8.83)$ \\
\hline \multicolumn{10}{|c|}{ Age group, $n(\%)$} \\
\hline$<65$ years & $343(100)$ & $205(59.77)$ & $157(76.59)$ & $26(12.68)$ & $22(10.73)$ & $138(40.23)$ & $122(88.41)$ & $10(7.25)$ & $6(4.35)$ \\
\hline $65-74$ years & $333(100)$ & $202(60.66)$ & 109 (53.96) & $47(23.27)$ & $46(22.77)$ & $131(39.34)$ & 94 (71.76) & $22(16.79)$ & $15(11.45)$ \\
\hline$\geq 75$ years & $400(100)$ & $179(44.75)$ & $82(45.81)$ & 49 (27.37) & $48(26.82)$ & $221(55.25)$ & $133(60.18)$ & $53(23.98)$ & $35(15.84)$ \\
\hline $\begin{array}{l}\text { Median age, } \\
\text { years (Q1/ } \\
\text { Q3) }\end{array}$ & $70(62 / 78)$ & $69(61 / 77)$ & & & & $73(63 / 80)$ & & & \\
\hline \multicolumn{10}{|l|}{ Stage, $n(\%)$} \\
\hline I & $245(100)$ & $148(60.41)$ & $90(60.81)$ & $28(18.92)$ & $30(20.27)$ & 97 (39.59) & $72(74.23)$ & $15(15.46)$ & $10(10.31)$ \\
\hline II & $292(100)$ & $157(53.77)$ & $94(59.87)$ & 29 (18.47) & 34 (21.66) & $135(46.23)$ & $95(70.37)$ & $22(16.30)$ & $18(13.33)$ \\
\hline III & $309(100)$ & $164(53.07)$ & $102(62.20)$ & 35 (21.34) & $27(16.46)$ & $145(46.93)$ & $102(70.34)$ & 27 (18.62) & $16(11.03)$ \\
\hline IV & $230(100)$ & $117(50.87)$ & $62(52.99)$ & $30(25.64)$ & 25 (21.37) & $113(49.13)$ & $80(70.80)$ & $21(18.58)$ & $12(10.62)$ \\
\hline \multicolumn{10}{|c|}{ Primary treatment, $n(\%)$} \\
\hline Surgery & $921(100)$ & $498(54.07)$ & $298(59.84)$ & $106(21.29)$ & $94(18.88)$ & $423(45.93)$ & $304(71.87)$ & $73(17.26)$ & $46(10.87)$ \\
\hline Other $^{\mathrm{b}}$ & $155(100)$ & $88(56.77)$ & $50(56.82)$ & $16(18.18)$ & $22(25.00)$ & $67(43.23)$ & 45 (67.16) & $12(17.91)$ & $10(14.93)$ \\
\hline
\end{tabular}

$C C I$ Charlson Comorbidity Index, $R C C$ Right-sided colon cancer, $L C R C$ Left-sided colorectal cancer

${ }^{\mathrm{a} C a t e g o r i a l}$ variables are given as numbers $(\%)$; median age is a continuous variable given in years (Q1/Q3)

${ }^{\mathrm{b}}$ Radiotherapy, radio-chemotherapy, chemotherapy or non-tumor-specific therapy

${ }^{\mathrm{c}} \mathrm{CCI}$ groups $(0,1,2+)$ are indicated within sex 


\section{Results}

Table 2 illustrates the characteristics of 586 men and 490 women with CRC overall and by sex. LCRC was more common in males (57\%) and RCC in females (52\%). More men than women were diagnosed at an early tumor stage I or II (57\%). Half as many RCC cases as LCRC cases were diagnosed at tumor stage I. At tumor stages II, III and IV more RCC cases were diagnosed (Fig. 1). Median age at diagnosis was higher in women ( 73 years) compared to their male counterparts (69 years). In the age group $\geq 75$ years more female than male CRC patients were observed (55\% versus $45 \%$ ).

$59 \%$ of the male patients and $71 \%$ of the female patients had no comorbidities. Overall, women had fewer comorbidities than men, even at an older age. For both men and women more than a third of the observed comorbidities were cardiovascular diseases including myocardial infarction, congestive heart failure, peripheral vascular disease and cerebrovascular disease. In descending order, men were also frequently affected by diabetes without target organ, chronic lung disease and peptic ulcer disease. In women, other frequent comorbidities were diabetes without target organ, peptic ulcer and moderate to severe renal disease (Table 1).
Table 3 shows the probability of receiving surgery versus another primary treatment depending on sex, subsite (LCRC versus RCC), CCI, tumor stage and age. Primary treatment option was dependent on subsite and CCI. For patients with a CCI $2+$ the probability of receiving primary treatment other than surgery was nearly twice as high [CCI $2+$ : odds ratio $(\mathrm{OR})=1.86$ (95\% confidence interval (CI) 1.08-3.23)] as for CRC patients with CCI 0. We observed a statistically significant interaction effect for sex on the association between CCI and primary treatment option ( $p$-interaction $=0.010$; Table 3 ), such that the effect of the association between having a CCI of $2+$ and receiving other primary treatment than surgery was stronger in women $[\mathrm{OR}=2.56(95 \%$ CI $0.94-6.98)]$ than in men $[\mathrm{OR}=1.54$ (95\% CI 0.78-3.04)]. All patients with RCC were significantly less likely to receive another primary treatment [OR 0.25 (95\% CI 0.15-0.42)] than surgery. The treatment option did not depend on tumor stage and age. Female patients had the same chance as male patients of receiving any primary treatment option [OR 1.03 (95\% CI 0.72-1.49)].

Next, we examined whether differences in survival existed between male and female CRC patients. Survival decreased with higher CCI, tumor stage and age in both men and women (Table 4; Fig. 2). CRC patients of
Fig. 1 Colorectal cancer subsite distribution grouped by tumor stages (I-IV). RCC Right-sided colon cancer, $L C R C$ Left-sided colorectal cancer

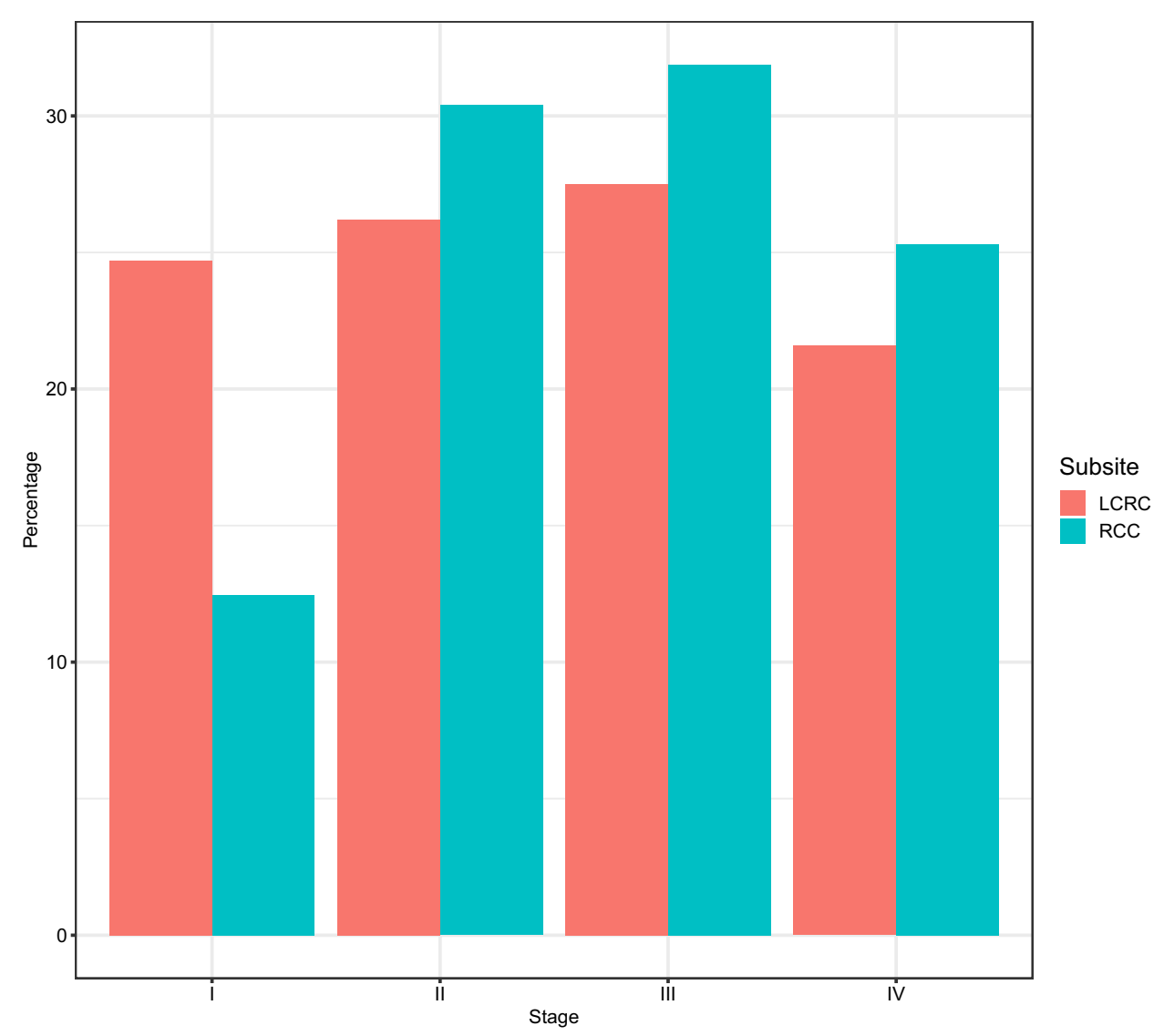




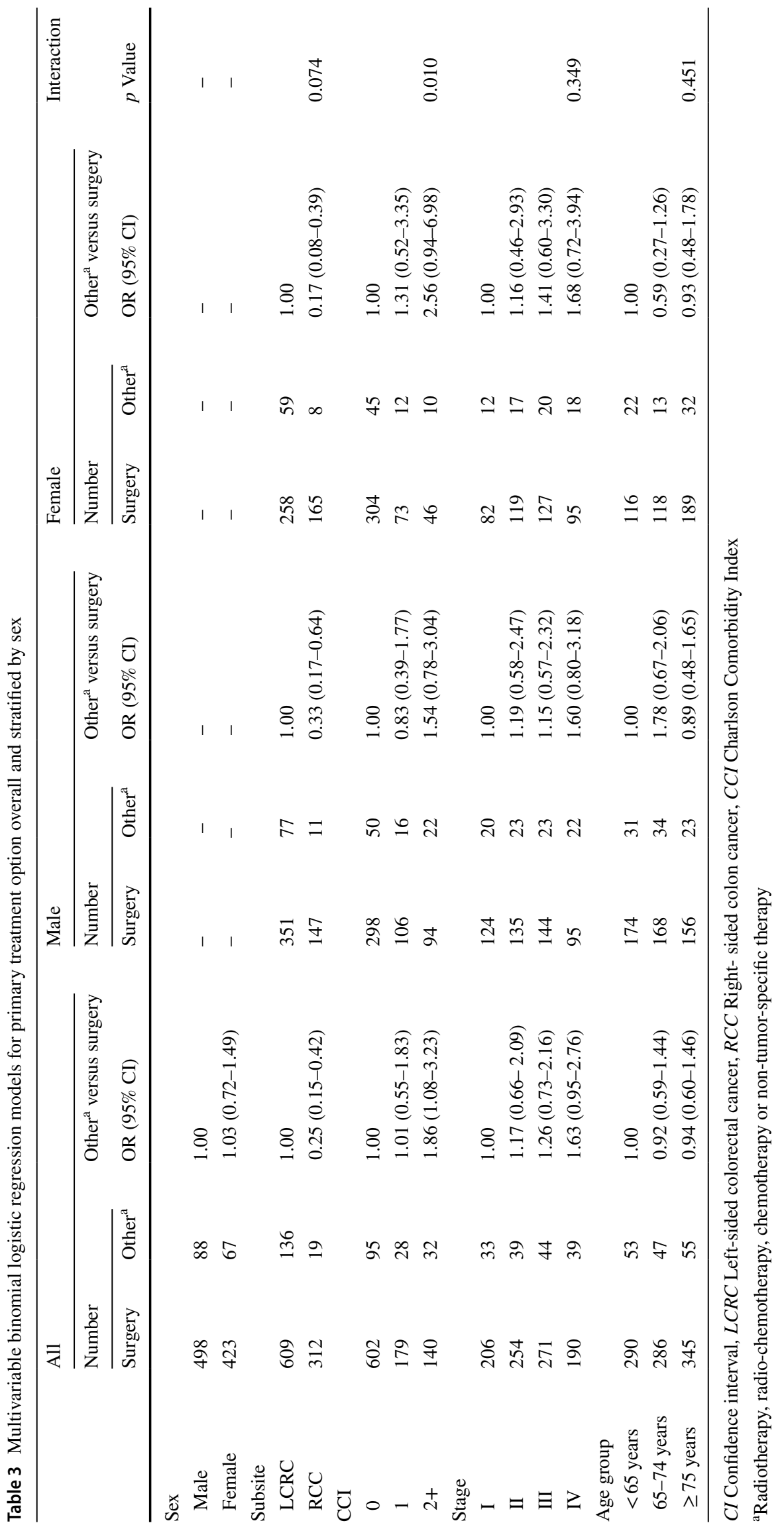


Table 4 Univariable and multivariable Cox regression models for survival analysis overall and stratified by sex

\begin{tabular}{|c|c|c|c|c|c|c|c|c|}
\hline & \multicolumn{2}{|l|}{ All } & \multicolumn{2}{|l|}{ Male } & \multicolumn{2}{|l|}{ Female } & \multicolumn{2}{|l|}{ Interaction } \\
\hline & Univariable & Multivariable & Univariable & Multivariable & Univariable & Multivariable & Univariable & Multivariable \\
\hline & HR $(95 \% \mathrm{CI})$ & HR (95\% CI) & HR (95\% CI) & HR (95\% CI) & HR (95\% CI) & HR $(95 \%$ CI $)$ & $p$ Value & $p$ Value \\
\hline \multicolumn{9}{|l|}{ Sex } \\
\hline Male & 1.00 & 1.00 & - & - & - & - & - & - \\
\hline Female & $\begin{array}{l}1.14(0.98- \\
1.33)\end{array}$ & $\begin{array}{l}1.04(0.89- \\
1.22)\end{array}$ & - & - & - & - & - & - \\
\hline \multicolumn{9}{|l|}{ Subsite } \\
\hline LCRC & 1.00 & 1.00 & 1.00 & 1.00 & 1.00 & 1.00 & & \\
\hline $\mathrm{RCC}$ & $\begin{array}{l}1.25(1.07- \\
1.47)\end{array}$ & $\begin{array}{l}1.02(0.85- \\
1.21)\end{array}$ & $\begin{array}{l}1.20(0.96- \\
1.52)\end{array}$ & $\begin{array}{l}1.02(0.80- \\
1.31)\end{array}$ & $\begin{array}{l}1.27(1.02- \\
1.59)\end{array}$ & $\begin{array}{l}1.03(0.81- \\
1.32)\end{array}$ & 0.750 & 0.928 \\
\hline \multicolumn{9}{|l|}{$\mathrm{CCI}$} \\
\hline 0 & 1.00 & 1.00 & 1.00 & 1.00 & 1.00 & 1.00 & & \\
\hline 1 & $\begin{array}{l}1.96(1.56- \\
2.44)\end{array}$ & $\begin{array}{l}1.57(1.24- \\
1.99)\end{array}$ & $\begin{array}{l}2.14(1.56- \\
2.93)\end{array}$ & $\begin{array}{l}1.66(1.21- \\
2.29)\end{array}$ & $\begin{array}{l}1.88(1.36- \\
2.59)\end{array}$ & $\begin{array}{l}1.51(1.07- \\
2.13)\end{array}$ & & \\
\hline $2+$ & $\begin{array}{l}2.07(1.66- \\
2.59)\end{array}$ & $\begin{array}{c}2.02(1.58 \\
-2.58)\end{array}$ & $\begin{array}{c}2.42(1.80 \\
-3.24)\end{array}$ & $\begin{array}{c}2.26(1.65 \\
-3.10)\end{array}$ & $\begin{array}{l}2.11(1.43- \\
3.12)\end{array}$ & $\begin{array}{l}1.73(1.12- \\
2.69)\end{array}$ & 0.761 & 0.309 \\
\hline \multicolumn{9}{|l|}{ Stage } \\
\hline I & 1.00 & 1.00 & 1.00 & 1.00 & 1.00 & 1.00 & & \\
\hline II & $\begin{array}{l}1.85(1.40- \\
2.45)\end{array}$ & $\begin{array}{l}1.76(1.32- \\
2.35)\end{array}$ & $\begin{array}{l}2.01(1.39- \\
2.93)\end{array}$ & $\begin{array}{l}1.99(1.36- \\
2.90)\end{array}$ & $\begin{array}{l}1.64(1.07- \\
2.52)\end{array}$ & $\begin{array}{l}1.51(0.97- \\
2.32)\end{array}$ & & \\
\hline III & $\begin{array}{l}2.92(2.23- \\
3.82)\end{array}$ & $\begin{array}{l}3.18(2.43- \\
4.17)\end{array}$ & $\begin{array}{l}2.73(1.91- \\
3.91)\end{array}$ & $\begin{array}{l}3.08(2.13- \\
4.43)\end{array}$ & $\begin{array}{l}3.09(2.08- \\
4.62)\end{array}$ & $\begin{array}{l}3.27(2.18- \\
4.89)\end{array}$ & & \\
\hline IV & $\begin{array}{l}11.70(8.88- \\
15.30)\end{array}$ & $\begin{array}{l}13.90(10.45- \\
18.56)\end{array}$ & $\begin{array}{l}12.70(8.80- \\
18.30)\end{array}$ & $\begin{array}{c}16.30(11.0 \\
-24.10)\end{array}$ & $\begin{array}{l}10.40(6.91- \\
15.70)\end{array}$ & $\begin{array}{c}11.80(7.73- \\
18.03)\end{array}$ & 0.949 & 0.623 \\
\hline \multicolumn{9}{|l|}{$\begin{array}{l}\text { Primary Treat- } \\
\text { ment }\end{array}$} \\
\hline Surgery & 1.00 & 1.00 & 1.00 & 1.00 & 1.00 & 1.00 & & \\
\hline Other $^{\mathrm{a}}$ & $\begin{array}{l}1.71(1.40- \\
2.09)\end{array}$ & $\begin{array}{l}2.04(1.65- \\
2.53)\end{array}$ & $\begin{array}{l}1.77(1.36- \\
2.31)\end{array}$ & $\begin{array}{l}2.14(1.61- \\
2.85)\end{array}$ & $\begin{array}{l}1.64(1.22- \\
2.23)\end{array}$ & $\begin{array}{l}1.87(1.35- \\
2.58)\end{array}$ & 0.736 & 0.602 \\
\hline \multicolumn{9}{|l|}{ Age group } \\
\hline$<65$ years & 1.00 & 1.00 & 1.00 & 1.00 & 1.00 & 1.00 & & \\
\hline $65-74$ years & $\begin{array}{l}1.36(1.09- \\
1.68)\end{array}$ & $\begin{array}{l}1.51(1.21- \\
1.88)\end{array}$ & $\begin{array}{l}1.40(1.06- \\
1.84)\end{array}$ & $\begin{array}{l}1.49(1.12- \\
2.00)\end{array}$ & $\begin{array}{l}1.29(0.92- \\
1.81)\end{array}$ & $\begin{array}{l}1.51(1.07- \\
2.13)\end{array}$ & & \\
\hline$\geq 75$ years & $\begin{array}{l}2.85(2.35- \\
3.46)\end{array}$ & $\begin{array}{l}3.10(2.53- \\
3.82)\end{array}$ & $\begin{array}{l}2.68(2.06- \\
3.49)\end{array}$ & $\begin{array}{l}2.78(2.09- \\
3.71)\end{array}$ & $\begin{array}{l}2.99(2.25- \\
4.00)\end{array}$ & $\begin{array}{l}3.48(2.57- \\
4.71)\end{array}$ & 0.433 & 0.216 \\
\hline
\end{tabular}

$H R$ Hazard ratio, $C I$ Confidence interval, $L C R C$ Left-sided colorectal cancer, $R C C$ Right-sided colon cancer, $C C I$ Charlson Comorbidity Index ${ }^{a}$ Radiotherapy, radio-chemotherapy, chemotherapy or non-tumor-specific therapy

either sex had basically twice the risk to die after another primary treatment than after surgery [Hazard ratio $(H R)=2.04(95 \%$ CI 1.65-2.53)]. Sex had no impact on survival (Fig. 2).

\section{Discussion}

We used the data of the largest cantonal cancer registry in Switzerland to evaluate differences in primary treatment option and survival between women and men diagnosed with CRC in 2000 and 2001. The results of our study indicate that in the Swiss Canton of Zurich female CRC patients had the same probability as male CRC patients of receiving surgery or another primary treatment. However, a statistically significant interaction effect indicated that sex influences the association between CCI and primary treatment option, such that the effect of the association between having a CCI $2+$ and receiving other primary treatment than surgery was stronger in women than in men. Furthermore, in this patient cohort having made adjustments for age, subsite, CCI, tumor stage and primary treatment option, men and women with CRC had equal overall survival.

According to the World Health Organization (WHO) global report on prevention of chronic diseases published in 2006, chronic diseases affect men and women almost equally 
A

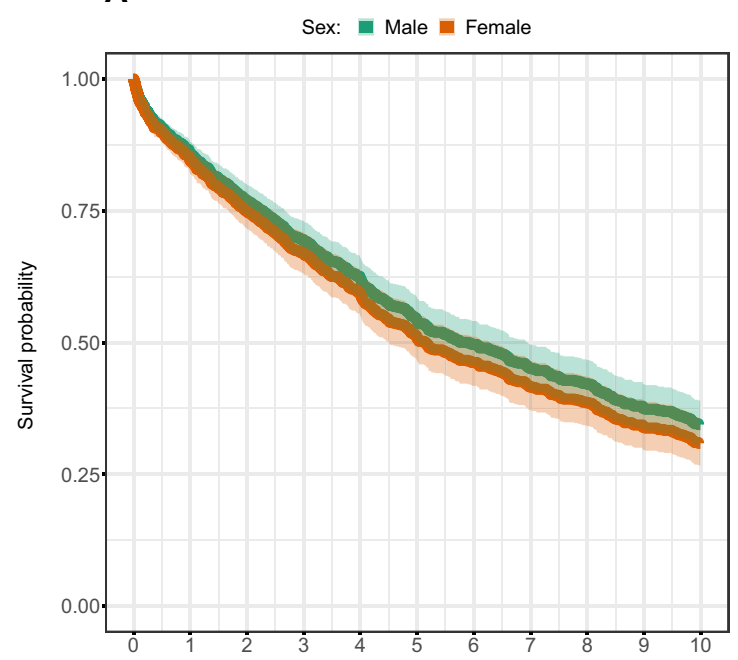

C

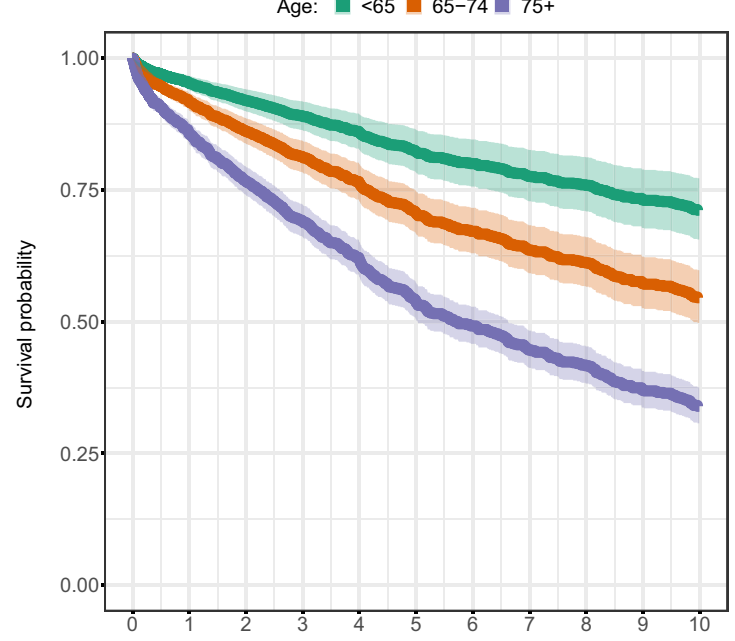

E

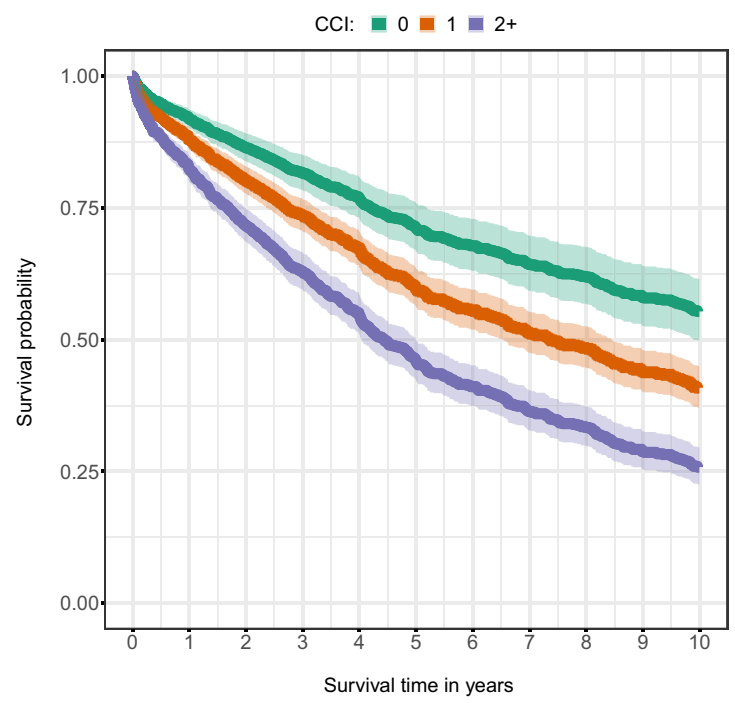

B

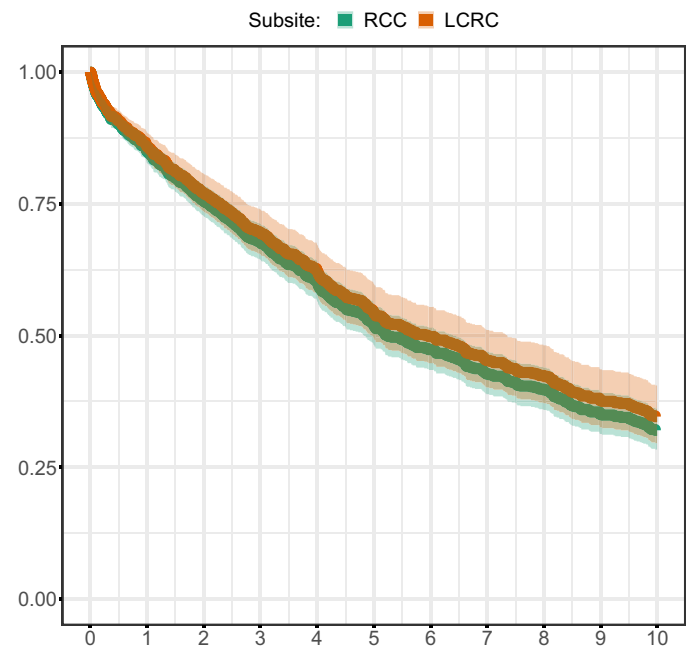

D

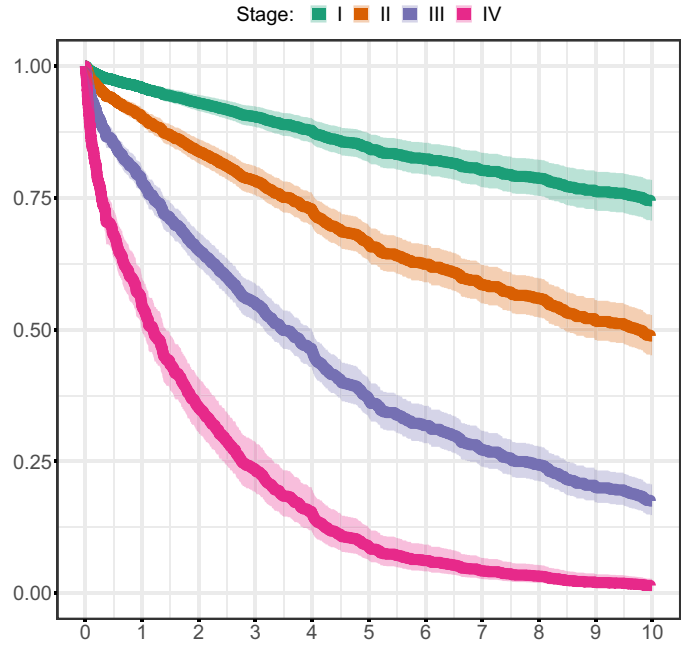

$\mathbf{F}$

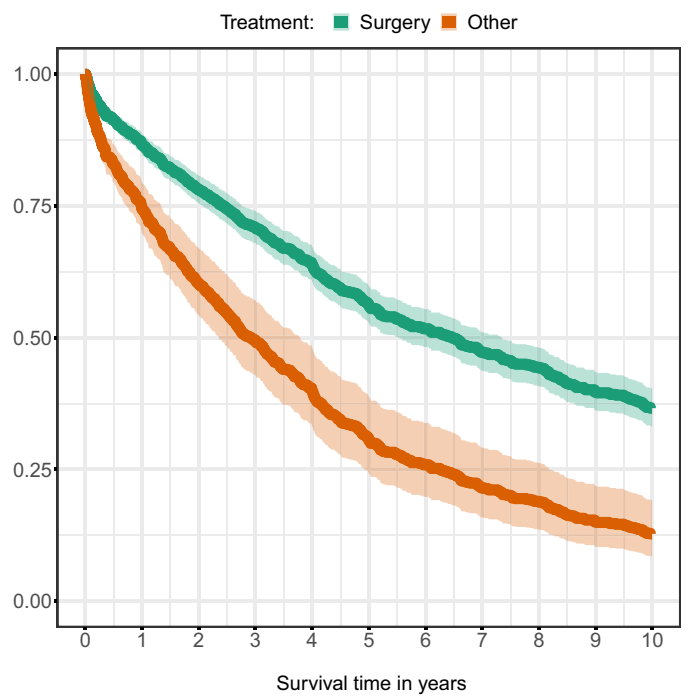

Fig. 2 Adjusted Kaplan-Meier survival curves with confidence bands for CRC patients stratified by a sex, $\mathbf{b}$ subsite, $\mathbf{c}$ age, $\mathbf{d}$ tumor stage, e CCI (Charlson Comorbidity Index), $\mathbf{f}$ primary treatment option. All results were mutually adjusted for all variables 
(Tunstall-Pedoe 2006). It is known that comorbidity is common in CRC patients (Sarfati et al. 2011). Our data are comparable with the worldwide cancer incidence and mortality report using data of the GLOBOCAN 2012 project, stating that the incidence of CRC in populations over 65 years of age is higher for women than for men (Ferlay et al. 2015). Female CRC patients are diagnosed at an older age compared with men as already shown in previous studies (Brenner et al. 2007; Paulson et al. 2009). At the same time, using the CCI, women in our patient cohort had a better underlying general state of health than men. Similarly, Katzenstein et al. (2018) observed that male rectal cancer patients developed a higher overall morbidity than women. Additionally, they reported a higher presence of risk factors such as alcohol and nicotine abuse, as well as higher body mass index (BMI) in male patients (Katzenstein et al. 2018). Cigarette smoking increases the risk of chronic diseases such as cardiovascular and chronic lung diseases but also of CRC (Johnson et al. 2013). Unfortunately, we did not have risk factor information available for our analysis and could not determine which factors were associated with the presence of comorbidity in men and in women. Future studies are needed to validate whether female CRC patients generally have a better health status than male CRC patients.

Our study revealed that the primary treatment option was dependent on CCI and subsite. In 2016, Sarfati et al., reviewed current knowledge of comorbidity in cancer patients and its impact on cancer diagnosis, treatment, and patient outcomes. They reported that cancer patients with comorbidity were generally less likely to receive curative treatment for their cancer than those without comorbidity (Sarfati et al. 2016). This is in line with other findings, in particular for CRC patients (Cronin et al. 2006; Gross et al. 2007; Khrizman et al. 2013; Lemmens et al. 2005a). In our study, although both treatment options, i.e., surgery and another primary treatment, contained both curative and palliative intentions, increasing CCI reduced the probability of surgical treatment. We hypothesize that increasing CCI reduced the probability of receiving curative surgical treatment. To address the challenges of comorbidity in cancer, Sarfati et al. (2016) proposed to improve the assessment of comorbidities among cancer patients and also to improve evidence from which to make cancer treatment decisions. This is particularly desirable, because cancer patients with comorbidity are often excluded from clinical trials leading to inconsistency in cancer treatment decisions. For cancer treatment decisions, it is common that simultaneously occurring comorbidities are considered as a "single-disease", because the complex interrelations of cancer treatment and number, type and severity of comorbidities are mostly unknown. Our results indicate that biological sex influences the impact of $\mathrm{CCI}$ on primary treatment option. Hence, it would be interesting to examine the quality of comorbidity assessment and whether this differs between men and women. Moreover, knowledge about how different types of comorbidity interact with CRC and its treatment in men and in women could optimize treatment decisions.

Due to the number of patients, we stratified primary treatment options into two groups and observed that the probability of receiving a primary treatment other than surgery was higher for LCRC (including rectal cancers) than for RCC. In the last two decades of the twentieth century treatment strategy in rectal cancer has changed regarding surgical techniques and adjuvant therapy. Concerning adjuvant therapy several studies have found a lower recurrence rate after adding preoperative radiotherapy to surgery in patients with resectable rectal cancer (Gérard et al. 1988; Goldberg et al. 1994; Horn et al. 1990; Jones et al. 1989). Furthermore, a Swedish rectal cancer trial revealed in 1997 a significant increase in overall survival in patients who received preoperative radiotherapy followed by surgery compared to patients who received surgery only (Cedermark et al. 1997). Probably this supported the introduction of the recommendation to apply neoadjuvant radiotherapy in rectal cancer patients at least in some European countries such as the Netherlands and France (Martijn et al. 2003; NN 1995). To the best of our knowledge no Swiss guidelines in rectal cancer management existed at the incidence years 2000 and 2001. As we only considered the first therapy administered without information on treatment intention, we cannot say for certain whether radiotherapy as the first therapy applied for rectal cancer was neoadjuvant radiotherapy.

In our study, men and women had the same probability of receiving any primary treatment option. Only a few studies have investigated sex differences on treatment option in CRC patients. Paulson et al. reported that women with advanced tumor stage were treated with less aggressive medical therapy, especially at an older age (Paulson et al. 2009). Similarly, Lemmens et al. (2005a, b) observed that the odds of receiving adjuvant therapy for CRC patients with tumor stage III depended on age and comorbidity but also on sex, and that women were less likely to be treated with adjuvant chemotherapy (Lemmens et al. 2005b). However, in our findings women in the highest CCI group appeared more likely to receive other therapy than surgery in comparison to men. The reasons for this potential disadvantage in female patients with concomitant diseases to receive optimal CRC treatment are unclear. Further investigations should determine the factors influencing cancer treatment choice in both men and women. Also, this illustrates the importance of standardized comorbidity assessment in the cancer treatment decision process to better ensure optimal therapy.

In this patient cohort, having made adjustments for age, subsite, CCI, tumor stage and primary treatment option, we observed that men and women with CRC had equal overall survival. In the literature of the last two decades, findings 
concerning sex differences on survival of CRC patients are inconsistent. Katzenstein et al. (2018) found no sex differences in oncological long-term results for rectal cancer patients after surgery including total morbidity in the multivariable analysis. Lydrup et al. (2015) observed equal survival for men and women with rectal cancer after correction for the underlying mortality in the population knowing that women generally live longer than men. This is in contrast to most previous publications, which observed a survival advantage for women after surgical treatment (McArdle et al. 2003; Paulson et al. 2009; Storli et al. 2011; Wichmann et al. 2001). It is important to note that none of these investigations had taken comorbidities into account.

In line with our results, comorbidity has consistently been found to have an adverse impact on CRC survival (Gross et al. 2006; Munro and Bentley 2004; Rieker et al. 2002; Sarfati et al. 2009). A plausible reason why comorbidity in CRC patients influences survival might be the direct impact of the underlying conditions on mortality. Nevertheless, there might also be indirect reasons for this effect. We found a significant impact of comorbidity on survival using multivariable cox regression models. As discussed above, it has been shown that patients with comorbidity receive less curative cancer treatment than patients without comorbidity. This is also true for our study, where the chance of receiving surgical treatment decreased with increasing comorbidity. In addition, it is impossible to exclude an adverse impact of cancer and its treatment on comorbidity development and progression. For instance, a locally spreading tumor, paraneoplastic syndrome, chemotherapy or hormonal therapy could affect the risk of cardiovascular, metabolic, and other diseases and exacerbate preexisting comorbidities. The importance of a better understanding of the interrelations between cancer, its treatment and the comorbidities is obvious.

We observed that RCC patients were more likely to be female and had more advanced tumor stages. These observations are consistent with other studies (Benedix et al. 2010; Hansen and Jess 2012; Leijssen et al. 2018). We observed in the univariable analysis that all patients with RCC and women with RCC had worse survival than their respective counterparts with LCRC. However, after multivariable adjusting this effect was attenuated and no longer statistically significant. Similarly, Leijssen et al. observed no association between tumor location and survival after adjustment for several factors including pathological factors such as differentiation and microsatellite instability (Leijssen et al. 2018). This is in contrast with other studies including a meta-analysis that reported worse survival in patients with right-sided colon cancer than with left-sided colon cancer (Benedix et al. 2010; Yahagi et al. 2016).

Some limitations of our study have to be taken into account. Due to a reduced number of patients in several treatment groups, it was not possible to create more than two treatment categories in our analysis. We were also not able to include additional risk factors such as smoking, dietary habits or seeking medical advice. We had missing information on T-category, $\mathrm{N}$-category and comorbidities. However, we used imputation methods and a comparison between a complete-case analysis and the imputed analysis revealed similar results. Finally, we would like to mention that immortal time bias cannot be excluded completely. Since we do not know the date when the treatment started, we do not know if the time period between diagnosis and start of treatment differed for the two treatment groups. The major strengths of our study were the data quality and the inclusion of the CCI. We used data from the largest cancer registry in Switzerland, where all incidence cases are registered with information on place of diagnosis, allowing us to add the parameters CCI, tumor stage and primary treatment option for the incidence years 2000 and 2001.

\section{Conclusion}

In this patient cohort, after adjustment for sex, tumor subsite, $\mathrm{CCI}$, tumor stage and age, women had the same chance as men to receive any primary treatment option for CRC cancer and overall survival did not differ by sex. However, comorbidity impacts survival and a further analysis revealed that the impact of comorbidity on primary treatment option depended on sex. Women in the highest CCI group appeared more likely to receive other therapy than surgery in comparison to men. Comorbidity is an important interacting and prognostic factor for CRC, but the complex interrelations between comorbidity, cancer and its treatment are still largely unknown. Here, targeted investigations by respecting sex should contribute to fill the gaps in modern individualized medicine resulting in improvement of prevention measures, treatment planning and outcome for male and female CRC patients.

Supplementary Information The online version contains supplementary material available at https://doi.org/10.1007/s00432-021-03557-y.

Author contributions SD, SR, KLM and ML designed the research. DK managed the data set. Collection and assembling of the data were assured by GP, KLM and ML. KLM performed the statistical analysis assisted by EM. Presentation of statistical results was optimized by LH. ML wrote the manuscript. SR and ML substantively revised the manuscript. GP and ML edited the manuscript. All authors contributed suggestions for improvement and approved the final manuscript.

Funding Open Access funding provided by Universität Zürich. This study was supported by the Alfred und Anneliese Sutter-Stöttner Stiftung. Ms Limam was supported by the Cancer League Zurich.

Data transparency The datasets generated and/or analyzed during the current study are not publicly available due to individual privacy 
reasons, but are available from the corresponding author on reasonable request.

\section{Compliance with ethical standards}

Conflict of interest The authors have no conflicts of interest to declare that are relevant to the content of this article.

Ethics approval For the incidence years 2000 and 2001, the cancer cases in the Canton of Zurich were registered with presumed consent and registration based on a decision by the Zurich Government Council from 1980 and the general registry approval by the Federal Commission of Experts for professional secrecy in medical research from 1995. All data were used anonymously in this analysis, and no approval from the Ethical Committee of the Canton of Zurich was necessary.

Open Access This article is licensed under a Creative Commons Attribution 4.0 International License, which permits use, sharing, adaptation, distribution and reproduction in any medium or format, as long as you give appropriate credit to the original author(s) and the source, provide a link to the Creative Commons licence, and indicate if changes were made. The images or other third party material in this article are included in the article's Creative Commons licence, unless indicated otherwise in a credit line to the material. If material is not included in the article's Creative Commons licence and your intended use is not permitted by statutory regulation or exceeds the permitted use, you will need to obtain permission directly from the copyright holder. To view a copy of this licence, visit http://creativecommons.org/licenses/by/4.0/.

\section{References}

Benedix F, Kube R, Meyer F, Schmidt U, Gastinger I, Lippert H (2010) Comparison of 17,641 patients with right- and left-sided colon cancer: differences in epidemiology, perioperative course, histology, and survival. Dis Colon Rectum 53:57-64. https://doi. org/10.1007/DCR.0b013e3181c703a4

Boakye D, Rillmann B, Walter V, Jansen L, Hoffmeister M, Brenner H (2018) Impact of comorbidity and frailty on prognosis in colorectal cancer patients: a systematic review and meta-analysis. Cancer Treat Rev 64:30-39. https://doi.org/10.1016/j.ctrv.2018.02.003

Bodner TE (2008) What Improves with Increased Missing Data Imputations? Struct Equ Model Multidiscipl J 15:651-675. https://doi. org/10.1080/10705510802339072

Bordoni A, Lorez M, Bouchardy C, Konzelmann I, Clough-Gorr K, and the NICER Working Group (2012) Trends in Colorectal Cancer Survival in Switzerland. Schweizerische Arbeitsgemeinschaft für klinische Krebsforschung SAKK, Schweizer Krebsbulletin, vol Nr. 1/2012

Brenner H, Hoffmeister M, Arndt V, Haug U (2007) Gender differences in colorectal cancer: implications for age at initiation of screening. Br J Cancer 96:828-831. https://doi.org/10.1038/sj.bjc.6603628

Bufill JA (1990) Colorectal cancer: evidence for distinct genetic categories based on proximal or distal tumor location. Ann Intern Med 113:779-788

Cedermark B, Dahlberg M, Glimelius B, Påhlman L, Rutqvist LE, Wilking $N$ (1997) Improved survival with preoperative radiotherapy in resectable rectal cancer. N Engl J Med 336:980-987. https://doi.org/10.1056/nejm199704033361402

Charlson ME, Pompei P, Ales KL, MacKenzie CR (1987) A new method of classifying prognostic comorbidity in longitudinal studies: development and validation. J Chronic Dis 40:373-383
Cronin DP, Harlan LC, Potosky AL, Clegg LX, Stevens JL, Mooney MM (2006) Patterns of care for adjuvant therapy in a random population-based sample of patients diagnosed with colorectal cancer. Am J Gastroenterol 101:2308-2318. https://doi.org/10.1 $111 /$ j.1572-0241.2006.00775.x

Ferlay J et al (2015) Cancer incidence and mortality worldwide: sources, methods and major patterns in GLOBOCAN 2012. Int J Cancer 136:E359-386. https://doi.org/10.1002/ijc.29210

Forman DBF, Gombe Mbalawa C, Kohler B, Piceros M, SteliarovaFoucher E, Swaminathan R and Ferlay J (eds) (2013) Cancer Incidence in Five Continents, Volume X (electronic version: http:// ci5.iarc.fr)

Gérard A et al (1988) Preoperative radiotherapy as adjuvant treatment in rectal cancer. Final results of a randomized study of the European Organization for Research and Treatment of Cancer (EORTC). Ann Surg 208:606-614. https://doi.org/10.1097/00000 658-198811000-00011

Goldberg PA, Nicholls RJ, Porter NH, Love S, Grimsey JE (1994) Long-term results of a randomised trial of short-course low-dose adjuvant pre-operative radiotherapy for rectal cancer: reduction in local treatment failure. Eur J Cancer 30:1602-1606. https://doi. org/10.1016/0959-8049(94)00312-s

Goldstein LB, Samsa GP, Matchar DB, Horner RD (2004) Charlson Index comorbidity adjustment for ischemic stroke outcome studies. Stroke 35:1941-1945. https://doi.org/10.1161/01.STR.00001 35225.80898.1c

Gross CP, Guo Z, McAvay GJ, Allore HG, Young M, Tinetti ME (2006) Multimorbidity and survival in older persons with colorectal cancer. J Am Geriatr Soc 54:1898-1904. https://doi.org/10 $.1111 / \mathrm{j} .1532-5415.2006 .00973 . x$

Gross CP, McAvay GJ, Guo Z, Tinetti ME (2007) The impact of chronic illnesses on the use and effectiveness of adjuvant chemotherapy for colon cancer. Cancer 109:2410-2419. https://doi. org/10.1002/cncr.22726

Hansen IO, Jess P (2012) Possible better long-term survival in left versus right-sided colon cancer-a systematic review. Dan Med J 59:A4444

Hayes SN (2006) Preventing cardiovascular disease in women. Am Fam Phys 74:1331-1340

Horn A, Halvorsen JF, Dahl O (1990) Preoperative radiotherapy in operable rectal cancer. Dis Colon Rectum 33:823-828. https:// doi.org/10.1007/BF02051916

Janssen-Heijnen ML, Houterman S, Lemmens VE, Louwman MW, Maas HA, Coebergh JW (2005a) Prognostic impact of increasing age and co-morbidity in cancer patients: a population-based approach. Crit Rev Oncol Hematol 55:231-240. https://doi. org/10.1016/j.critrevonc.2005.04.008

Janssen-Heijnen ML, Maas HA, Lemmens VE, Houterman S, Louwman WJ, Verheij CD, Coebergh JW (2005b) The correlation of age and comorbidity with therapy and survival in cancer patients in North-Brabant and North-Limburg, 1995-2001. Ned Tijdschr Geneeskd 149:1686-1690

Johnson CM, Wei C, Ensor JE, Smolenski DJ, Amos CI, Levin B, Berry DA (2013) Meta-analyses of colorectal cancer risk factors. Cancer Causes Control 24:1207-1222. https://doi.org/10.1007/ s10552-013-0201-5

Jones DJ, Zaloudik J, James RD, Haboubi N, Moore M, Schofield PF (1989) Predicting local recurrence of carcinoma of the rectum after preoperative radiotherapy and surgery. Br J Surg 76:11721175. https://doi.org/10.1002/bjs. 1800761120

Katzenstein J, Steinert R, Ptok H, Otto R, Gastinger I, Lippert H, Meyer F (2018) Gender-specific differences of the early postoperative and oncosurgical long-term outcome in rectal cancer-data obtained in a prospective multicenter observational study. Chirurg. https://doi.org/10.1007/s00104-018-0634-1 
Khrizman P et al (2013) Postoperative adjuvant chemotherapy use in patients with stage II/III rectal cancer treated with neoadjuvant therapy: a national comprehensive cancer network analysis. J Clin Oncol 31:30-38. https://doi.org/10.1200/jco.2011.40.3188

Kim SE, Paik HY, Yoon H, Lee JE, Kim N, Sung MK (2015) Sexand gender-specific disparities in colorectal cancer risk. World J Gastroenterol 21:5167-5175. https://doi.org/10.3748/wjg.v21. i17.5167

Lee DS, Donovan L, Austin PC, Gong Y, Liu PP, Rouleau JL, Tu JV (2005) Comparison of coding of heart failure and comorbidities in administrative and clinical data for use in outcomes research. Med Care 43:182-188. https://doi.org/10.1097/00005650-20050 2000-00012

Lee GH, Malietzis G, Askari A, Bernardo D, Al-Hassi HO, Clark SK (2015) Is right-sided colon cancer different to left-sided colorectal cancer? A systematic review. Eur J Surg Oncol 41:300-308. https ://doi.org/10.1016/j.ejso.2014.11.001

Leijssen LGJ, Dinaux AM, Kunitake H, Bordeianou LG, Berger DL (2018) Pathologic factors are more important than tumor location in long-term survival in colon cancer. Int J Colorectal Dis 33:709-717. https://doi.org/10.1007/s00384-018-3027-5

Lemmens VE, Janssen-Heijnen ML, Verheij CD, Houterman S, Repelaer van Driel OJ, Coebergh JW (2005a) Co-morbidity leads to altered treatment and worse survival of elderly patients with colorectal cancer. Br J Surg 92:615-623. https://doi.org/10.1002/ bjs. 4913

Lemmens VE, van Halteren AH, Janssen-Heijnen ML, Vreugdenhil G, Repelaer van Driel OJ, Coebergh JW (2005b) Adjuvant treatment for elderly patients with stage III colon cancer in the southern Netherlands is affected by socioeconomic status, gender, and comorbidity. Ann Oncol 16:767-772. https://doi.org/10.1093/ annonc/mdi159

Lorez M, Marbet U, Arndt V (2016) Subsite-specific colorectal cancer trends in Switzerland (1989-2012). Schweizer Krebsbulletin 1:67-74

Lydrup ML, Hoglund P (2015) Gender aspects of survival after surgical treatment for rectal cancer. Colorectal Dis 17:390-396. https ://doi.org/10.1111/codi.12871

Martijn H, Voogd AC, van de Poll-Franse LV, Repelaer van Driel OJ, Rutten HJT, Coebergh JWW (2003) Improved survival of patients with rectal cancer since 1980: a population-based study. Eur J Cancer 39:2073-2079. https://doi.org/10.1016/S0959 -8049(03)00493-3

McArdle CS, McMillan DC, Hole DJ (2003) Male gender adversely affects survival following surgery for colorectal cancer. Br J Surg 90:711-715. https://doi.org/10.1002/bjs.4098

Moons KG, Donders RA, Stijnen T, Harrell FE Jr (2006) Using the outcome for imputation of missing predictor values was preferred. J Clin Epidemiol 59:1092-1101. https://doi.org/10.1016/j.jclin epi.2006.01.009

Mounier-Vehier C, Boudghene F, Delsart P, Claisse G, Kpogbemadou N, Debarge V, Letombe B (2014) Heart, arteries and women, a care pathway for women at high cardiovascular risk. Ann Cardiol Angeiol (Paris) 63:192-196. https://doi.org/10.1016/j.ancar d.2014.05.001

Mounier-Vehier C, Delsart P, Letombe B (2010) Cardiovascular risks differences in women: how can we improve the management? Presse Med 39:234-241. https://doi.org/10.1016/j. lpm.2009.10.013

Munro AJ, Bentley AH (2004) Deprivation, comorbidity and survival in a cohort of patients with colorectal cancer. Eur J Cancer Care (Engl) 13:254-262. https://doi.org/10.111 1/j.1365-2354.2004.00480.x

Myers RP, Quan H, Hubbard JN, Shaheen AA, Kaplan GG (2009) Predicting in-hospital mortality in patients with cirrhosis: results differ across risk adjustment methods. Hepatology 49:568-577. https://doi.org/10.1002/hep.22676

Nakayama G, Tanaka C, Kodera Y (2013) Current options for the diagnosis, staging and therapeutic management of colorectal cancer. Gastrointest Tumors 1:25-32. https://doi.org/10.1159/000354995

NN (1995) Le choix thérapeutique dans le cancer du rectum. In: Conférence de consensus, Paris, 1994. ANDEM, Agence Nationale pour le Développement et l'Evaluation Médicale

Paulson EC, Wirtalla C, Armstrong K, Mahmoud NN (2009) Gender influences treatment and survival in colorectal cancer surgery. Dis Colon Rectum 52:1982-1991. https://doi.org/10.1007/DCR.0b013 e3181beb42a

Puymirat E et al (2012) Association of changes in clinical characteristics and management with improvement in survival among patients with ST-elevation myocardial infarction. JAMA 308:9981006. https://doi.org/10.1001/2012.jama.11348

Rieker RJ, Hammer E, Eisele R, Schmid E, Hogel J (2002) The impact of comorbidity on the overall survival and the cause of death in patients after colorectal cancer resection. Langenbecks Arch Surg 387:72-76. https://doi.org/10.1007/s00423-002-0291-0

Sarfati D et al (2009) The effect of comorbidity on the use of adjuvant chemotherapy and survival from colon cancer: a retrospective cohort study. BMC Cancer 9:116. https://doi. org/10.1186/1471-2407-9-116

Sarfati D, Koczwara B, Jackson C (2016) The impact of comorbidity on cancer and its treatment. CA Cancer J Clin 66:337-350. https ://doi.org/10.3322/caac.21342

Sarfati D, Tan L, Blakely T, Pearce N (2011) Comorbidity among patients with colon cancer in New Zealand. N Z Med J 124:76-88

Sobin LH, Gospodarowicz MK, Wittekind C (2009) TNM classification of malignant tumours, 7th edn. Wiley-Blackwell, Oxford

Sogaard M, Thomsen RW, Bossen KS, Sorensen HT, Norgaard M (2013) The impact of comorbidity on cancer survival: a review. Clin Epidemiol 5:3-29. https://doi.org/10.2147/clep.s47150

Storli KE et al (2011) Overall survival after resection for colon cancer in a national cohort study was adversely affected by TNM stage, lymph node ratio, gender, and old age. Int J Colorectal Dis 26:1299-1307. https://doi.org/10.1007/s00384-011-1244-2

Therneau TM (2015) A Package for Survival Analysis in S

Tunstall-Pedoe H (2006) Preventing Chronic Diseases. A Vital Investment: WHO Global Report. Geneva: World Health Organization, 2005. pp 200. CHF 30.00. ISBN 924 1563001. Also published on http://www.who.int/chp/chronic_disease_report/en vol 35. Int J Epidemiol. https://doi.org/10.1093/ije/dy1098

Van Buuren S (2018) Flexible imputation of missing data. Chapman and Hall/CRC, Hoboken

van Buuren S, Groothuis-Oudshoorn K (2011) mice: multivariate imputation by chained equations in R. J Stat Softw 45:1-67. https ://doi.org/10.18637/jss.v045.i03

Venables WN, Ripley BD (2002) Modern Applied Statistics with S. 4th ed. Springer Publishing Company, New York

Vulto AJ, Lemmens VE, Louwman MW, Janssen-Heijnen ML, Poortmans PH, Lybeert ML, Coebergh JW (2006) The influence of age and comorbidity on receiving radiotherapy as part of primary treatment for cancer in South Netherlands, 1995 to 2002. Cancer 106:2734-2742. https://doi.org/10.1002/cncr.21934

White IR, Royston P, Wood AM (2011) Multiple imputation using chained equations: issues and guidance for practice. Stat Med 30:377-399. https://doi.org/10.1002/sim.4067

Wichmann MW, Muller C, Hornung HM, Lau-Werner U, Schildberg FW (2001) Gender differences in long-term survival of patients with colorectal cancer. Br J Surg 88:1092-1098. https://doi.org/1 0.1046/j.0007-1323.2001.01819.x

Wickham H (2016) ggplot2: elegant graphics for data analysis. Springer, New York 
Yahagi M, Okabayashi K, Hasegawa H, Tsuruta M, Kitagawa Y (2016) The worse prognosis of right-sided compared with left-sided colon cancers: a systematic review and meta-analysis. J Gastrointest Surg 20:648-655. https://doi.org/10.1007/s11605-015-3026-6
Publisher's Note Springer Nature remains neutral with regard to jurisdictional claims in published maps and institutional affiliations. 